\title{
Author's Reply to: Central Blood Pressure: A Possible Latent Factor Affecting CAVI
}

We thank Dr. Tomiyama and Prof. Yamashina for their insightful comments on our article ${ }^{1)}$.

CAVI originates from stiffness parameter beta ${ }^{2)}$, but has a different index applied to the artery with some length, in which pulse wave velocity can be measured $^{3)}$. Theoretically, blood pressure must be obtained at each every point from the origin of the aorta to the tibial artery at the ankle. The problem is that blood pressure increases from the origin of the aorta to the femoral artery, and decreases from the peripheral artery. Conveniently, the mean blood pressure of the whole artery could be applied. In place of the mean blood pressure of the whole artery, blood pressure at the brachial artery was applied ${ }^{3)}$. The rationale for this is difficult to prove directly; however, the validity is supported and accepted by many reports, including the effects of blood pressure-lowering agents $^{4-(-6)}$, weight reduction ${ }^{7)}$ and smoking cessation ${ }^{8)}$, and also in our report ${ }^{3)}$. Therefore, the application of brachial blood pressure is thought to be appropriate. At least, the application of central blood pressure, if it could be measured, is theoretically inappropriate.

Two concerns were raised by Dr. Tomiyama and Prof. Yamashina.

1. Beta blockers lower the central blood pressure to a lesser degree than the brachial artery. So if central blood pressure is applied, the possibility that CAVI is correlated with blood pressure remains.

This concern was derived from a misunderstanding of CAVI. As mentioned above, the blood pressure of the whole artery should be applied but it is impossible. Based on the assumption that brachial blood pressure might be representative of the mean blood pressure of the whole artery, brachial blood pressure is applied. Even though the effect of beta blockers on central blood pressure is less than on the peripheral artery, the blood pressure applied for CAVI includes the peripheral artery. The effect of beta blockers on central pressure could therfore be negligible. Actually, we observed that baPWV decreased by beta blockers, as shown in Fig. $\mathbf{1 A}^{1)}$. It is known that PWV is affected by blood pressure at the measuring time. This decrease in baPWV indicates that the blood pressure in the whole artery was decreased by beta blockers.

The independence of CAVI from blood pressure at the measuring time could be strongly supported by these data ${ }^{2)}$.
2. CAVI may reflect peripheral arterial stiffness rather than the stiffness of the large arteries.

This comment is partly right. CAVI reflects the stiffness of both the large artery and peripheral artery; however, it is unclear how much \% of CAVI is derived from the large elastic artery and from the peripheral artery. The extent to which the \% of CAVI reflects hard matrix consisting of collagens and elastins, or smooth muscle cells is also unclear. From accumulated data on the change of CAVI, CAVI changes during a relatively short term, for one month to 6 months, during weight reduction ${ }^{7)}$, blood glucose control $^{\text {9) }}$ and hypertension control ${ }^{4-6)}$. CAVI also changes in a few hours by an alpha blocker, doxazosin, accompanying a decrease in blood pressures (Fig. 1, B in Ref. 1). These results indicated that CAVI reflects not only arteriosclerosis composed of mainly collagen, elastin fibers as hard matrix, but also reflects the contraction of smooth muscle cells subjected to various stress on the artery. Further studies are required to clarify the contributing factors for CAVI.

Open discussion is welcomed to better understand the new field of CAVI. Thank you again.

\section{References}

1) Shirai K, Song M, Suzuki J, Kurosu T, Oyama T, Nagayama D, Miyashita Y, Yamamura S, Takahashi M: Contradictory effects of $\beta 1$ - and $\alpha 1$ - aderenergic receptor blockers on cardio-ankle vascular stiffness index (CAVI) - CAVI is independent of blood pressure-. J Atheroscler Thromb, 2011; 18: 49-55

2) Hayashi K, Handa H, Nagasawa S, Okumura A, Moritake K: Stiffness and elastic behavior of human intracranial and extracranial arteries. J Biomech, 1980; 13: 175-184

3) Shirai K, Utino J, Otsuka K, Takata M: A novel blood pressure-independent arterial wall stiffness parameter; cardio-ankle vascular index (CAVI). J Atheroscler Thromb, 2006; 13: 101-107

4) Kinouchi K, Ichihara A, Sakoda M, Kurauchi-Mito A, Murohashi-Bokuda $\mathrm{K}$, Itoh $\mathrm{H}$ : Effects of telmisartan on arterial stiffness assessed by the cardio-ankle vascular index in hypertensive patients. Kidney Blood Press Res, 2010; 33: 304-312

5) Bokuda K, Ichihara A, Sakoda M, Mito A, Kinouchi K, Itoh $\mathrm{H}$ : Blood pressure-independent effect of candesartan on cardio-ankle vascular index in hypertensive patients with metabolic syndrome. Vasc Health Risk Manag, 2010; 6: $571-578$

6) Sasaki H, Saiki A, Endo K, Ban N, Yamaguchi T, Kawana H, Nagayama D, Ohhira M, Oyama T, Miyashita Y, Shi- 
rai K: Protective effects of efonidipine, a T- and L-type calcium channel blocker, on renal function and arterial stiffness in type 2 diabetic patients with hypertension and nephropathy. J Atheroscler Thromb, 2009; 16: 568-575

7) Satoh-Asahara N, Suganami T, Majima T, Kotani K, Kato Y, Araki R, Koyama K, Okajima T, Tanabe M, Oishi M, Himeno A, Kono, Sugawara A, Hattori M, Ogawa Y, Shimatsu, A and the Japan Obesity and Metabolic Syndrome Study (JOMS) Group Urinary Cystatin C as a Potential Risk Marker for Cardiovascular Disease and Chronic Kidney Disease inPatients with Obesity and Metabolic Syndrome. Clin J Am Soc Nephrol, 2011; 6: 265-273

8) Noike H, Nakamura K, Sugiyama Y, Iizuka T, Shimizu K, Takahashi M, Hirano K, Suzuki M, Mikamo H, Nakagami T, Shirai K: Changes in cardio-ankle vascular index in smoking cessation. J Atheroscler Thromb, 2010; 17: 517525

9) Nagayama D, Saiki A, Endo K, Yamaguchi T, Ban N, Kawana H, Ohira M, Oyama T, Miyashita Y, Shirai K: Improvement of cardio-ankle vascular index by glimepiri- de in type 2 diabetic patients. Int J Clin Pract, 2010; 64: $1796-1801$

\section{Kohji Shirai and Mao Takahashi}

Internal medicine, Sakura Hospital, Toho University, Chiba, Japan

Address for correspondence: Kohji Shirai, Internal medicine, Sakura Hospital, Toho University, Chiba, Japan

E-mail: kshirai@kb3.so-net.ne.jp

Received: March 24, 2011

Accepted for publication: April 8, 2011
A

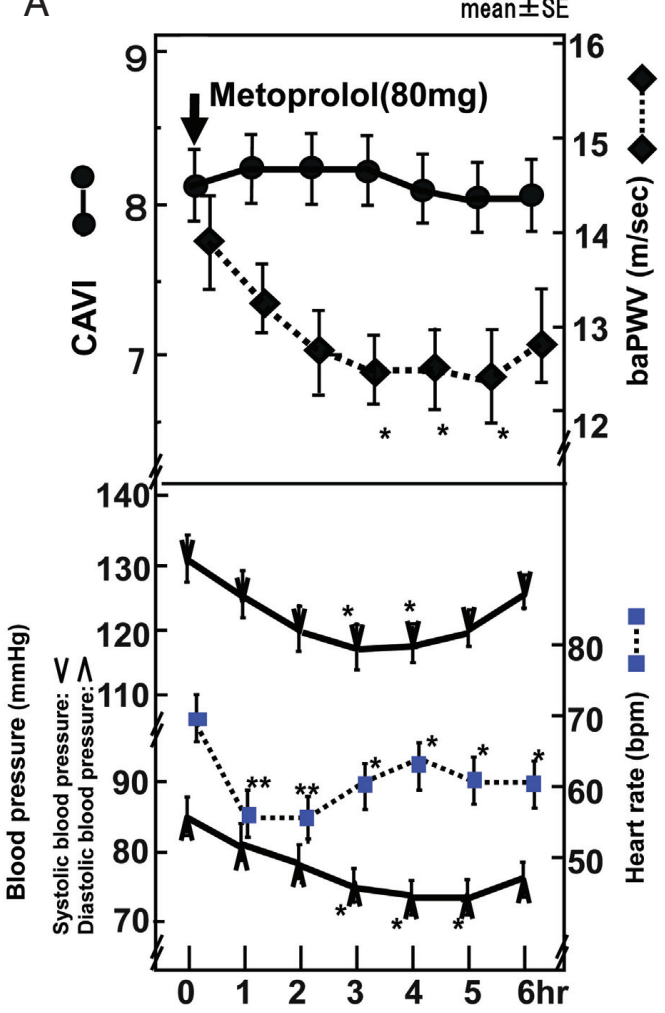

B

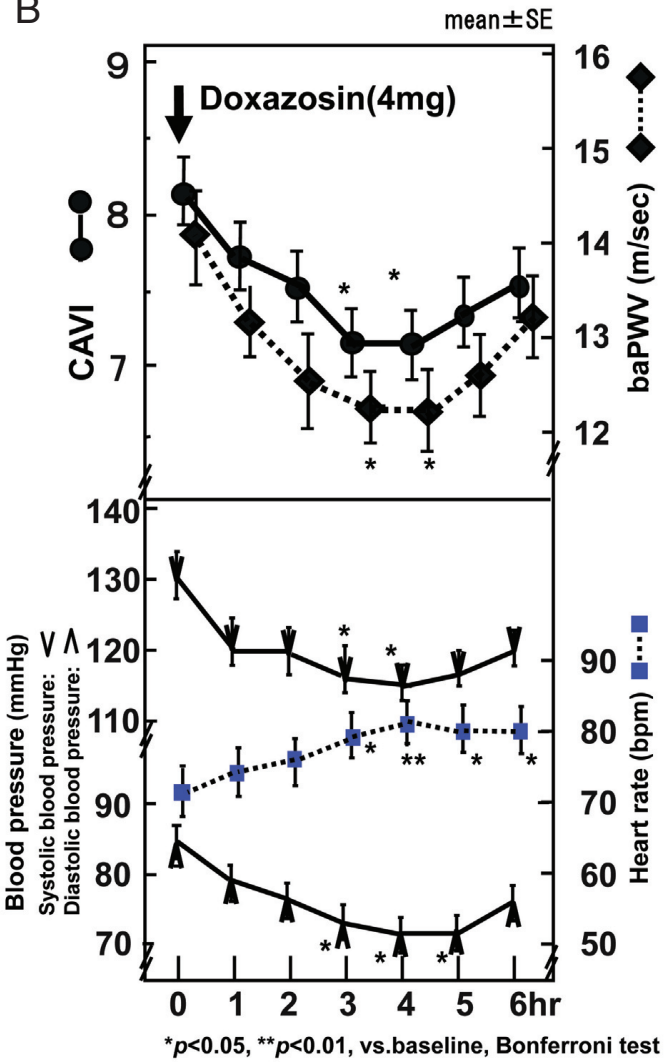

Fig. 1.

A.Effects of metoprolol on CAVI, baPWV, blood pressures and heart rate Metoprolol (80 mg) was administered to 12 men. CAVI, baPWV, systolic blood pressure, diastolic blood pressure and heart rate were measured every hour for 6 hours.

B.Effects of doxazosin on CAVI, baPWV, blood pressure and pulse rate Doxazosin $(4 \mathrm{mg}$ ) was administered to 12 men. CAVI, baPWV, systolic blood pressure, diastolic blood pressure and heart rate were measured every hour for 6 hours. 